\title{
Family Language Policy, Language Practice, Motivation, and Planning among Israeli Arab Students in Wingate Institute's Preparatory Program
}

\author{
Orly $\operatorname{Kayam}^{1} \&$ Tijana Hirsch ${ }^{2, *}$ \\ ${ }^{1}$ Zinman College at the Wingate Institute, Netanya 42902, Israel \\ *Corresponding author: Tel: 972-547-527-519Ｅ-mail: tijana-h@wincol.ac.il
}

Received: April 16, 2013 Accepted: May 23, 2013 Published: June 24, 2013

doi:10.5296/ije.v5i2.3532ＵRL: http://dx.doi.org/10.5296/ije.v5i2.3532

\begin{abstract}
Family language policy (FLP) and language use in different domains and relationships was investigated in thirteen Israeli-Arab students enrolled in an institution of higher education in Israel. Participants came from Arabic FLPs, communities, and schools. The study was completed through semi-structured interviews. Our research objectives were to investigate the FLP of the sample and a possible presence of differences in the ideologies concerning their parent-led FLP and their future family's FLP, among other things. Our findings point to a possible change in ideologies toward the instrumentally oriented FLP which incorporates Hebrew language to a greater degree. Further investigations should focus on effects of generational FLP change on identity and related psychological factors.
\end{abstract}

Keywords: family language policy; bilingualism; second language acquisition; language ideology; language in higher education 


\section{Introduction}

Most Israeli-Arabs live in Arabic speaking communities in Israel. Israeli-Arab children attend schools in Arabic in those communities and learn Hebrew as a second language. As there are currently no colleges or universities in Israel with Arabic as the language of instruction, Israeli-Arabs who attend or plan on attending colleges or universities in Israel are required to have a high level of Hebrew language knowledge. Furthermore, in many university programs, a high level of proficiency in English is expected, if not required, and this would be the third language learned by the Israeli-Arab students. In light of these facts, we are interested in investigating the bottom up or family language policy experiences and practices of Israeli-Arab students who are enrolled in an institution of higher learning in Israel. We want to investigate a potential generational shift in attitudes and perceptions of these students toward Hebrew language knowledge as compared to the FLP as led by their parents within the home they grew up in. We believe that explorations into the FLP of the families of these students and the students' emerging and future FLPs will provide important information on the experiences of the Israeli-Arabs who attend institutions of higher learning in Israel, or those who may want to pursue tertiary education in the future. It is intended to provide a glimpse into and stimulate interest in uncovering the language-related experiences not readily apparent but which may indicate changes occurring in segments of this community.

\subsection{Specialized Preparatory Program}

The Zinman College at the Wingate Institute is an institution that trains academicians in the field of physical education, and is a leader in Israel on the subject of physical education. It has set as a goal accessibility of higher education for young people from all over the country who are interested in the fields of physical education and sport.

This specialized preparatory program was established in 2005. It provides its graduates with a diploma, approved by the Council of Higher Education that can be used in lieu of a matriculation certificate for acceptance to Wingate's undergraduate program. This specialized program is the only one of its kind in Israel; no other academic institution has a specialized program in the field of physical education and sport. A significant number of the students in the program come from a low socio-economic background (residents of the periphery, minorities, new immigrants from the former USSR, Ethiopians, etc.), a third of whom have learning disabilities. The students are funded by the State of Israel.

\section{Program Goals}

(1) Strengthening the college and increasing the number of students who study there

(2) Preparing students for college level studies

(3) Training sports instructors for the periphery, youth villages, etc.

(4) Giving opportunities to youths, mostly army veterans, to acquire an academic education in a specialized field

(5) Raising awareness in the fields of physical activity and promoting health 


\section{Literature Review}

Language policy is "...an effort by someone who has or claims authority to modify the language practice or language ideology of other people (Spolsky, 1999b). Language policy can be approached top-down stemming from national and local government offices and such or it can be viewed from the bottom-up, stemming from individuals and the family, with each family member exerting their own claims of authority to modify language practice and ideology within the family. Language ideology, in turn, refers to beliefs toward language practice (Silverstein, 1979). Much research has focused on the top-down language policy practices, management, and ideologies, with bottom-up approach through family language policy (FLP) investigations only recently gaining recognition and attention in the research community. Family language policy looks at the family unit and its participants or different family members and investigates different relationships, ideologies, and practices of those family members and the effects of their stance on other participants within the family, negotiating, consciously or not, the language policy within that family. FLP does not form in a vacuum; it is affected by top-down policies, such as government and community policies, educational institutional policies, and others, as well as the de-facto policies of the surroundings. The way that the participants view and respond to these top-down policies no doubt affects their own ideologies and practices, as do the ideologies and practices of the other family members. Different participants, family members, within the family may hold a different status in formation of the FLP, with parents, for example, initially setting the FLP of the family, but all participants or family members eventually exerting their own ideologies and practices onto others, always negotiating and renegotiating the FLP of the family. King, Fogle, and Logan -Terry (2008) view FLP as a merging of two fields, that of language policy and child language acquisition, and rightfully so, as the language policy negotiated between the parents will be their children's initial language acquisition experience, until they start exerting their own ideologies upon the family.

It is important when looking at family language policies to examine the ideologies, practices, and management of different family members at different times. Recently there have been several studies carried out examining the parent-led FLP of different linguistic communities of parents with young children around the world and more specifically in Israel. Kayam and Hirsch (2012) investigated the English speaking community's parent-led FLP within Israel. The study was interested in uncovering the ideologies and practices of this community, as well as management approaches as exhibited through selections of preschool/kindergarten settings based on the language policy of that establishment (Hebrew, English, or bilingual), among other foci. The general finding of these studies points to highly integrated society with high level of fluency in Hebrew as well as the FLP which strives to maintain the English language within the home and through careful management techniques involving selection of appropriate linguistic environment in early child care settings. Family language policies of the Russian speaking community in Israel from the former Soviet Union as well as the Amharic 
speaking community in Israel from Ethiopia have also been examined (see Schwartz \& Moin, 2011; Moin, Schwartz, \& Breitkopf, 2011; Golan-Cook \& Olshtain, 2011, Stavans, 2012). Findings point to different experiences and FLPs rooted in numbers (of speakers), ideology or strength of conviction toward heritage language maintenance, strength and organization of the linguistic community, as well as instrumental factors. Immigration of these two groups “...75,000 Jews from Ethiopia and 800,000 from the former Soviet Union introduced major changes, not just in demography but also in linguistic ideology (Spolsky, 1999b)" in Israel. These three linguistic communities are very much present in Israel's linguistic repertoire. While English has a long standing history within Israel's linguistic landscape, Russian and Amharic's presence is mostly due to their relatively recent arrival to Israel. The Russian community is large and well organized, as well as "...convinced of the value of their culture and adopted language (Spolsky, 1999b),” and this is exhibited in their FLP practice, planning, and management. The Ethiopian community comes with very different social and economic challenges which have slowed down their integration and contributed to maintenance of their heritage language. In both cases, however, a shift in younger generations towards Hebrew is noted.

In the case of Arabic in Israel, it is important to note that Arabic is one of the two official national languages within Israel. Israel is the only non-Arab country in which Arabic is given that status. Amara (2002) explains: "Arabic is the mother tongue and the main national language of the Arab citizens of Israel. Arabic is likewise a community language of a not-significant percentage of Sephardic Jews. Arabic serves as the sole official language of the Arab countries neighboring Israel and benefits from a special prestige in the Islamic states. Arabic in Israel is a unique case. It was the main language until the establishment of Israel, when because of changing political circumstances it became a secondary language. Despite Arabic being the second official language it is not a competing partner in a dyadic bilingual state according to the classification by Lambert (1999).” In the current work we consciously choose not to delve into the history and politics of the linguistic communities within Israel as it is beyond the scope of this work, instead we focus on language practices and more specifically, the aim is to investigate the attitude of a small number of adult Israeli-Arabs toward their parents'-led FLP as well as their own early FLP planning. In this work we explore the attitudes of young Israeli-Arab adults toward Arabic-Hebrew dyad and language practices. For more on the history and politics of Israel's linguistic communities, and more specifically Arabic in Israel see Landau 1987, Koplewitz 1992, Spolsky 1994, Spolsky and Shohamy 1999a, Spolsky 1999b, Ben-Rafael 1994, Amara 2002. Grosjean (2010)'s Complementary Principle states that bilinguals acquire and use languages in different domains and use them for different purposes and with different people in life. Languages are, in other words, compartmentalized on need-to-use basis. We are interested in exploring this compartmentalization and use of Arabic and Hebrew by Israeli-Arab students in order to get an understanding of the socio-linguistic experiences of this group.

Our research questions are as following:

1) What was the parent-led FLP practice of our participants? 
2) What is the early planning FLP of our participants as future Israeli-Arab parents?

3) Why do Israeli-Arabs learn Hebrew? (motives)

4) Which is the dominant language of our sample?

\section{Methods}

\subsection{Participants}

Thirteen Israeli-Arab students from the Zinman College at the Wingate Institute participated in our study. The mean age of participants was 22 years of age and number of children in the family was 5 . All of the students were enrolled in the specialized preparatory program at the college. At the time of the interviews, 232 students were enrolled in the first year of the preparatory program, 17 of which were Israeli-Arabs, 13 of which participated in our study. At the time of the interviews 12 out of the 13 participants lived in Israeli-Arab towns or communities and reported having grown up in that community or ones like it. One participant reported living in a bilingual Hebrew-Arabic speaking community.

\subsection{Semi-Structured Interview}

Participants were asked to answer a series of demographical questions, questions pertaining to their family's language policy (FLP), parental and participant proficiency levels in Hebrew, and their attitudes toward parent-led FLP. The interviews were conducted in Hebrew. Participants were asked about their age, number of siblings, their birth order, place of birth, and education level of the parents. FLP practice questions included questions on language use in communication between different family members within the home, proficiency levels in Hebrew of the participants, their mother, and father, participant's language use in thinking, dreaming, counting, reading books, newspapers, magazines, in watching television, listening to the radio, and in conversation with friends. FLP management through the education domain was addressed through questions on language use in early education settings, elementary school, middle school, and high school. The attitude toward the Hebrew-Arabic dyad and the FLP was addressed through two questions: In the first question they were asked to project their own FLP with their children in the future by selecting the intended language and degree of use on the Likert scale (Likert, 1932) ranging from 1 to 5, where 1 corresponded to Arabic only, 3 to bilingual Arabic-Hebrew, and 5 Hebrew only. The second question asked "If you could, would you change something about which or the amount of language your parents used with you? What? and Why?” Here the participants were given an opportunity to elaborate as much or as little as they wanted to.

Participation in the study was voluntary and no incentive was offered for participation. The nature and purpose of the study was explained individually to each participant at the onset of the interview. The interviews were performed over the phone and took 15 minutes to complete. Participants were thanked for their participation and were given the information about the researchers involved in the study. 


\section{MInstitute"}

\section{Results}

\subsection{Family Language Policy}

In order to get a clear picture of FLP practices we asked the students to rate on a scale from 1 to 5 (with one corresponding to Arabic only, 3 corresponding to bilingual Hebrew-Arabic, and 5 corresponding to Hebrew only) the language(s) used in different relationships within the family. In the following relationships all 13 students selected a rating of 1, corresponding to Arabic only: mother to me, father to me, me to mother, me to father, siblings to me, me to siblings. Between parents, Arabic only was chosen in 11 cases, mostly Arabic (rating of 2) in one case, and bilingual (rating of 3) in one case.

In rating their parents' proficiency in Hebrew, fathers were reported to be of higher fluency than mothers with a rating of 4 versus a 3 on a Likert scale, with 1 corresponding to no knowledge in Hebrew and 5 corresponding to native-level of fluency. Students rated their own fluency in Hebrew in three domains: speaking, reading, and writing, and in all three cases reported a native-level fluency (rating of 5) on average.

Participants were asked about their language use in different situations and activities (see Table 1):

Table 1: Participant's language use in different domains

\begin{tabular}{llll}
\hline Arabic only & Arabic and Hebrew & Hebrew only & Domain \\
\hline 10 & 3 & 0 & Thinking \\
9 & 4 & 0 & Dreaming \\
8 & 1 & 4 & Counting \\
8 & 3 & 1 & Reading books \\
3 & 4 & 6 & Reading newspapers \\
3 & 5 & 5 & Watching television \\
4 & 4 & 3 & Listening to the radio \\
4 & 9 & 0 & Communication (friends) \\
\hline
\end{tabular}

Education level of fathers was reported to be higher in four cases, and equal to mothers' in nine cases. Language in early education settings for all of the students was Arabic, as was the case in elementary, middle school and high school settings for all but one student, who attended bilingual Hebrew-Arabic schools from second grade onwards.

\subsection{Early FLP Planning}

When asked which language(s) they would speak with their children, in the future, four participants responded with Arabic only, seven participants responded with bilingual Arabic and Hebrew, and 1 participant reported planning on speaking mostly Hebrew with his/her children. One of the participants who plans on speaking Arabic only with her children added that it would also depend on her (future) partner.

\subsection{Attitudes toward the FLP}

When asked "If you could, would you change something about which or the amount of language your parents used with you? What? and Why?” The following were the responses: 
Participant 1: No, Arabic is my mother tongue and I plan on continuing with that language.

Participant 2: Yes, because we are in a Jewish country and all the time Hebrew is spoken, and there are people who don't speak Arabic and that could help him/her in the future.

Participant 3: No, we don't choose for our parents.

Participant 4: No, I don't mind, I grew up that way and I am used to it that way.

Participant 5: Yes, I would have preferred if they spoke to me in Hebrew as well so that I could feel/get to know the Jewish world and know how to speak. Because when we grow up and get into the world, in all the universities Hebrew is needed at a high level, we need to know Hebrew so we can succeed in our studies.

Participant 6: Yes, I would have wanted for my parents to have spoken more Hebrew with me, because it's difficult for me to deal with the materials in Hebrew at the college.

Participant 7: No, because we can learn Hebrew anywhere: from TV and the street, I don't need my parents for that.

Participant 8: No

Participant 9: No, language is the way to connect with people. I learned in my studies that if you want to, you can learn any language you want.

Participant 10: No, that's my mother tongue.

Participant 11: Yes, I would have preferred if they spoke to me in both Hebrew and Arabic as we live in Israel and it's important to know Hebrew well too.

Participant 12: Yes, I would have preferred if they spoke to me in Hebrew at home as well, as that would have helped me now in my studies.

Participant 13: No, it doesn't bother me that they spoke to me only in Arabic.

All of the participants who plan on speaking Arabic only in the future with their children responded to the above question by saying that they would not change their parents'-led FLP. Three participants who reported planning on speaking both Hebrew and Arabic equally with their children also said that they would not change their parents'-led FLP. All of the participants who reported planning to speak both Hebrew and Arabic in the future, with their children also answered in the affirmative to the question above (5/13).

To summarize, the answers to our research questions are as follows: the FLP of the home and between the FLP participants (family members) was in most cases and most relationships monolingual Arabic. Early planning of FLP for more than half of the participants has shifted to a desired bilingual Arabic-Hebrew FLP in their future families, from the monolingual paradigm they grew up in. The reason for this shift and for their desire for Hebrew, as narrated by our participants, seems to be solely instrumental. They recognize the need for higher-level Hebrew in order to reach their own educational and professional goals. 


\section{Discussion}

Hebrew is the dominant language in Israel. Israeli-Arabs most often attend Israeli Arab schools in which the primary language of instruction is Arabic and in which Hebrew is learned as the second language. Hebrew is encountered all around and "All age groups, regardless of gender, have informal contact with Hebrew speakers, though in varying degrees (Spolsky \& Cooper, 1991 as seen in Amara, 2002).” As evident through our small scale study, Israeli-Arabs desire Hebrew for instrumental reasons, for work, higher education learning, and opportunities. It is "...an important tool for all Arab citizens in Israel since it enables them to function effectively in all domains of life (Amara, 2002).” Our (albeit limited) sample of young Israeli-Arab adults who are interested in and enrolled in higher education settings is largely bilingual, as reported above, Hebrew is a large part of their linguistic repertoire, in books they read, radio and television programs they follow, to communication with friends. Arabic is the intimate language of the family, of dreaming, thinking, and counting, as reported by our participants. In asking the participants to report the language of thought, dreaming, and counting we were interested in uncovering the dominance of one language over the other. Although clearly bilingual, how bilingual were they? Thinking in colloquial terms refers to the "silent self-talk" (Pavlenko, 2011) or "thinking for speaking" (Slobin, 1996). It refers to our inner thoughts prior to speaking which indeed do occur in one of the languages we speak, depending on the situation or the domain. As mentioned above, Grosjean (2010)'s Complementary Principle states that bilinguals compartmentalize the language according to need and use. What we found is that our sample of Israeli-Arab students communicated dominance in Arabic over Hebrew in reporting Arabic as their language of thoughts. This finding points to higher frequency of use and perhaps the size of their social network in Arabic, according to Dewaele's (2009) findings examining various factors influencing inner speech language choice.

Bilinguals often report dreaming in both languages depending on the situation and nature of the dream (Vildomec, 1963), our small number of participants confirm this finding, while most report dreaming in Arabic only, once again pointing to the dominance of Arabic over Hebrew, some do report dreaming in Hebrew as well.

Counting is accepted as a well learned behavior, and is not part of the Complementary Principle, it is instead exclusively controlled by the language in which it is learned (Grosjean, 2010). Our sample's responses to the language use in counting are surprising for four participants and challenge the above belief. Four participants reported using Hebrew for counting. All of the participants were raised in Arabic speaking families and attended schools in Arabic, and assuming that learning to count takes place early on in life, it should theoretically have been learned in Arabic and performed in Arabic throughout life. These four cases point to perhaps a higher proficiency levels in the second language (Hebrew) and point to the need for further probing and investigations on the subject of counting as a well learned behavior which is held exempt from the Complementary Principle. Perhaps it is not always so different, perhaps it, at least in some cases, still depends on age of acquisition of second language, age when counting was learned in the second language, and the frequency of use.

Arabic is not threatened and will most likely never be abandoned by Israeli-Arab speakers. 
Hebrew, on the other hand is very much recognized as the language of opportunity, as narrated by our participants above. Although bilingual, they wish to have better or higher command of Hebrew for purely instrumental reasons and this realization and desire may in fact influence future FLPs of future Israeli-Arab parents educated in the higher education institutions in Israel. There may very well be an increased proficiency in higher-level Hebrew among Israeli-Arabs. Our participants shed light on the tug of war between their appreciation and loyalty to Arabic and their instrumental need for Hebrew. Amara and Abu-Akel (1998) (from Amara 2002) state that Arabs learn Hebrew for communicative and instrumental reasons, and that highly educated Arabs have a higher command over Modern Standard Hebrew than Standard Arabic. Although we are unable to speculate on the level of command over the two languages, our study indeed supports the notion that Modern Standard Hebrew among those educated in institutions of higher learning is more sought after, and perhaps better known. Currently, there are no institutions of higher learning in Arabic in Israel, and this fact alone may be the motivator for higher Hebrew language fluency among young, motivated Israeli-Arabs. Instead of focusing on politics and negatives, as is often done with any sub-topic of Israel-Arab relationships we dare to focus on the positives of the bilingual and in some cases multilingual abilities of this group. We are impressed with the open minded points of view which embrace the second language as communicated by some of the participants.

Going broader, when looking at our findings within the FLP framework, we receive support for notions which state that within the family, different family members or the participants in the FLP have different ideologies at different times. At the moment, some of our participants express a difference in ideology to that of their parents and the home they grew up in. This change may or may not carry over into practice in their future FLPs in the next generation, depending on the strength of their beliefs and the negotiation for formulation of the policy with their partners, and later their children. Their parents, or future grandparents of their children, may still have influence over the future of the next generation's FLP. One of the limitations of this study is the sample size. The present study provides a glimpse into the presence of changing FLP ideologies within this community. A larger scale, longitudinal study should be performed in order to examine the extent of this shift and its consequences on different and numerous aspects affected by the change in FLP.

\section{Acknowledgements}

We would like to thank the students for participating in our study. Thank you to Michal Ben-Izhak Klutch for conducting the interviews and to Chaya Zipori for her help with the editing of this work. We appreciate your help. 


\section{References}

Amara, M. H. (2002a). The Place of Arabic in Israel. International Journal of the Sociology of Language, 158, 53-68.

Ben-Rafael, E. (1994). Language, Identity, and Social Division: The Case of Israel. Oxford Studies in Language Contact. Oxford: Oxford University Press.

Dewaele, J. M. (2009). Age effects on self-perceived communicative competence and language choice among adult multilinguals. Roberts, Leah, Georges Daniel Véronique, Anna Nilsson and Marion Tellier (Eds.)

Golan-Cook, P., \& Olshtain, E. (2011). A Model of Identity and Language Orientations: The Case of Immigrant Students from the Former Soviet Union in Israel. Journal of Multilingual and Multicultural Development, 32(4), 361-376. http://dx.doi.org/10.1080/01434632.2011.579128

Grosjean, F. (2010). Bilingual: Life and Reality. Cambridge, Mass: Harvard University Press.

Kayam, O., \& Hirsch, T. (2012). Family Language Policy of the English Speaking Immigrant Community in Israel: Families with Young Children and their FLP Planning and Management. International Journal of Linguistics, 4(4), 622-635. http://dx.doi.org/10.5296/ijl.v4i4.2631

Kayam, O., \& Hirsch, T. (2012). (In press). Israel's English Speaking Immigrant Parents' Family Language Policy Management: Language in the Education Domain. International Journal of Linguistics.

King K.A., Fogle, L., \& Logan-Terry, A. (2008). Family Language Policy. Language and $\begin{array}{lll}\text { Linguistics } & \text { Compass, } & \text { 907-922. }\end{array}$ http://dx.doi.org/10.1111/j.1749-818X.2008.00076.x

Koplewitz, I. (1992). Arabic in Israel: The Sociolinguistic Situation of Israel's Arab Minority. International Journal of the Sociology of Language, 98, 29-66. http://dx.doi.org/10.1515/ijsl.1992.98.29

Lambert, R. D. (1999). A Scaffolding for Language Policy. International Journal of the Sociology of Language, 137, 3-26. http://dx.doi.org/10.1515/ijsl.1999.137.3

Landau, J. (1987). Hebrew and Arabic in the State of Israel: Political aspects of the language issue. International Journal of Sociology and Language, 67, 117-133.

Likert, R. (1932). A Technique for Measurement of Attitudes. Archives of Psychology, 140, 5-55.

Moin, V., Schwartz, M., \& Breitkopf, A. (2011). Balancing between heritage and host languages in bilingual kindergarten: viewpoints of Russian-speaking immigrant parents in Germany and in Israel. European Early Childhood Education Research Journal, 19(4), 515-533. http://dx.doi.org/10.1080/1350293X.2011.623530 


\section{Macrothink}

International Journal of Education

ISSN 1948-5476

2013, Vol. 5, No. 2

Pavlenko, A. (2011). Thinking and Speaking in Two Languages. Bristol/Buffalo/Toronto: Multilingual Matters.

Schwartz, M., \& Moin, V. (2011). PArents' assessment if their preschool children's bilingual development in the context of family language policy. Journal of Multilingual and Multicultural

Development, 33(1),

35-55. http://dx.doi.org/10.1080/01434632.2011.638078

Silverstein, M. (1979). "Language structure and linguistic ideology.” In Paul R. Clyne (ed.), The Elements: A parasession on linguistic units and levels. Chicago: Chicago Linguistic Society 193-247.

Slobin, D. I. (1996a). From "thought and language" to "thinking for speaking." In J. J. Gumperz \& S. C. Levinson(Eds.), Rethinking linguistic relativity (pp. 70-96). Cambridge: Cambridge University Press.

Spolsky, B. (1994). The situation of Arabic in israel. In Arabic Sociolinguistics: Issues and Perspectives, Yasir Suleiman (Ed.), 227-234. London: Curzon.

Spolsky, B., \& Cooper, R. (1991). The languages of Jerusalem. Oxford: Clarendon.

Spolsky, B., \& Shohamy, E. (1999a). Language in Israeli Society and Education. International Journal of the Sociology of Language, 137, 93-114. Adalah's Newsletter, Volume 29, October 2006.

Spolsky, B. (1999b). Languages of Israel: Policy, Ideology and Practice. Clevedon: Multilingual Matters Ltd.

Stavans A. (2012). Language policy and literacy practices in the family: the case of Ethiopian parental narrative input. Journal of Multilingual and Multicultural Development. Vildomec, V. (1963). Multilingualism. A. W. Sytho

\section{Copyright Disclaimer}

Copyright reserved by the author(s).

This article is an open-access article distributed under the terms and conditions of the Creative Commons Attribution license (http://creativecommons.org/licenses/by/3.0/). 